Editorial

\title{
The Journal of Fluids: An International and Interdisciplinary Scientific Open Access Journal
}

\author{
Bekir Sami Yilbas
}

Received: 16 November 2015; Accepted: 16 November 2015; Published: 4 January 2016

Editor-in-Chief of Journal of Fluids, Mechanical Engineering Department, King Fahd University of Petroleum and Minerals, KFUPM Box 1913, Dhahran 31261, Saudi Arabia; bsyilbas@kfupm.edu.sa; Tel.: +966-13-860-4481;

Fax: +966-13-860-2949

The science of fluids started from early civilizations when mankind understood the nature of channel flow. Archimedes discovered the hydrodynamics of floating bodies in early 250 B.C. Despite attempts to improve machine operation according to hydrodynamic principles-such as sailing vessels, intricate irrigation systems-fundamental improvements in fluid mechanics only started to take place in the 17th and 18th centuries. Newton's, Bernoulli's and Euler's work can be considered as being the initiation of structured formulations and understanding of flowing fluids. Although many aspects of fluid mechanic studies do not yield practical applications, for example in classical hydrodynamics, studies on fluid mechanics, as a whole, form the basis for progressing and understanding of fluid flow situations. In the early 19th century, combined efforts of mathematicians, physicists, and engineers triggered the advancement of fluids in terms of approaches to engineering problems. For example, the first paper of Reynolds [1] on turbulence, and his other work on principles of fluid mechanics, reshaped the understanding and formulation of high speed flow in fluid mechanics. In addition, the concept of a boundary layer introduced by Prandtl [2], significantly contributed to conceptual understanding of the solution of paradoxes related to flow of low viscosity fluids. In the late 18th century, Riemann's work on compression waves [3] opened a new window for fundamental comprehension of gas dynamics. Later, observations made by Mach [4] caused further development in supersonic flow of compressible fluids. The consequences of the facts faced during the First World War almost forced engineers and scientists to exclusively focus on compressible fluid flow because of the need to develop aircrafts such as fighter planes. Later, the search for solutions regarding compressible problems was escalated during the Second World War because of the demand to produce rockets and missiles. Currently, the space flight missions enables the continuation to search for answers for many unsolved problems in supersonic and hypersonic flows.

Recent developments in computer technology have enabled progression in all fields of fluids from micro/nano scale to macro scales. In addition, the science of fluids is advancing rapidly with the joint efforts of physicists and mathematicians. The challenges and the lessons learned from the solutions of analytical and numerical treatments of fluids problems improve the high level of understanding of fundamentals in fluid mechanics and lead to sophisticated designs of fluid systems. Although significant progress has been made in fluids over recent years, there are still challenging fundamental and practical problems in fluid mechanics, such as turbulence. Using time or space average equations to tackle turbulence problems is a current practice; however, no general analytical model that completely describes the nature of turbulence exists. In addition, further challenges such as analysis of nano-fluid flow, multi-phase mixtures, and non-Newtonian complex flow still need to be addressed in the near future.

In the Journal of Fluids, research concerning all aspects of flow conditions and the challenges of flow problems in nano/micro scale to macro scales in space, as well as transient to steady treatments, are welcome. This journal offers a base for disseminating knowledge and progress made in the area of fluids. The Editorial Board endorse the statement that research in fluids is one of the most essential 
requirements for the advancement of science and technology. The Journal of Fluids provides an advanced forum for studies on fluids theory and its applications, and fluid simulations, modeling, and experimentation in chemical, physics and biological processes. Our aim is to publish state-of-the-art papers, including original research papers, reviews, case reports, as well as technical notes and meeting reports. We assure the fluids community that we are fully committed to serve their needs and want to drive the Journal of Fluids to a position where it is recognized as a premier outlet for high quality, leading edge research. The key to that success is, of course, its readership and potential authors. On behalf of the Editorial Board, I invite you to submit your original work, review papers and suggestions for the Journal of Fluids. I look forward to reading your contributions.

\section{References}

1. Reynolds, O. An experimental investigation of the circumstances which determine whether the motion of water shall be direct or sinuous, and of the Law of Resistance in parallel channels. Philos. Trans. R. Soc. Lond. 1883, 174, 935-982. [CrossRef]

2. Prandtl, L. Über Flüssigkeitsbe-Wegung bei Sehr Kleiner Reibung; Internationalen Mathematiker-Kongresses: Heidelberg, Germany, 1904.

3. Riemann, B. Ueber Die Fortpflanzung Ebener Luftwellen von Endlicher Schwingungsweite; Ges(t)ammelte Werke: Leipzig, Germany, 1876.

4. Mach, E.; Salcher, P. Photographische Fixierung der durch Projectile in der Luft eingeleiteten Vorgänge. In Sitzungsberichte der Kaiserlichen Akademie der Wissenschaften. Mathematisch-Naturwissenschaftliche Classe, 95; Lynge \& Søn ILAB-LILA: Copenhagen, Denmark, 1887; pp. 764-780.

(C) 2016 by the author; licensee MDPI, Basel, Switzerland. This article is an open access article distributed under the terms and conditions of the Creative Commons by Attribution (CC-BY) license (http://creativecommons.org/licenses/by/4.0/). 